Arq. Bras. Med. Vet. Zootec., v.71, n.2, p.703-710, 2019

\title{
Substituição da farinha e do óleo de peixe por farinha e óleo de origem vegetal em rações utilizadas na fase de engorda do camarão-branco-do-pacífico Litopenaeus vannamei, em sistemas de bioflocos
}

\author{
[Replacement of fishmeal and fish oil with vegetable meal and oil in feedstuffs used in the \\ growing phase of the Pacific white shrimp Litopenaeus vannamei, in biofloc systems] \\ M.B. Tesser $^{1}$, A.P. Cardozo ${ }^{1}$, H.N. Camaño ${ }^{1,2}$, W. Wasielesky ${ }^{1}$ \\ ${ }^{1}$ Instituto de Oceanografia - Universidade Federal do Rio Grande - Rio Grande, RS \\ ${ }^{2}$ Aluno de pós-graduação - Universidade Federal do Rio Grande - Rio Grande, RS
}

\begin{abstract}
RESUMO
Este trabalho teve como objetivo avaliar o efeito da substituição da farinha e do óleo de peixe pelo concentrado proteico de soja e óleo de soja, na sobrevivência, no crescimento e na composição corporal dos camarões (Litopenaeus vannamei) produzidos em sistema de bioflocos (BFT). Foram formuladas cinco dietas, isoproteicas e isoenergéticas, com diferentes níveis de substituição da farinha e do óleo de peixe por concentrado proteico de soja e óleo de soja, sendo os tratamentos designados como: $0 \%$ (sem substituição), $25 \%, 50 \%, 75 \%$ e $100 \%$. As rações foram elaboradas para conter aproximadamente $35 \%$ de proteína e $8 \%$ de lipídios. O experimento foi conduzido durante 49 dias, com juvenis com peso inicial de $2,93 \pm 0,83 \mathrm{~g}$, em sistema de bioflocos (BFT). Não foram encontradas diferenças significativas entre os tratamentos até $75 \%$ de substituição para as variáveis de ganho de peso, conversão alimentar e sobrevivência. O tratamento de $100 \%$ de substituição apresentou menor taxa de crescimento específico. O presente resultado sugere que, nas dietas para camarões criados em sistema bioflocos, a farinha e o óleo de peixe possam ser substituídos em até $75 \%$ por concentrado proteico de soja e óleo de soja, sem prejudicar o desenvolvimento dos animais.
\end{abstract}

Palavras-chave: camarão marinho, farinha e óleo de peixe, concentrado proteico de soja, óleo de soja

\begin{abstract}
The objective of this work was to evaluate the effect of the substitution of fishmeal and fish oil with soy protein concentrate and soybean oil on survival, growth and body composition of shrimp (Litopenaeus vannamei) produced in biofloc system (BFT). Five diets were formulated to be isoproteic and isoenergetic with different levels of substitution of fishmeal and fish oil with soy protein concentrate and soybean oil. The treatments were named as: $0 \%$ (without substitution), 25\%, 50\%, 75\% and 100\%. The diets were formulated to contain approximately 35\% protein and $8 \%$ lipids. The experiment was conducted for 49 days, with juveniles with initial weight of $(2.93 \pm 0.83 \mathrm{~g})$ in a biofloc system (BFT). No significant differences were found between treatments up to $75 \%$ of substitution for the variables of weight gain, feed conversion ratio, and survival. The 100\% substitution treatment showed a lower specific growth rate. The present study suggests fish meal and fish oil can be substituted in up to $75 \%$ for soy protein concentrate and soybean oil, without harming the development of the shrimps when reared in biofloc system.
\end{abstract}

Keywords: marine shrimp, fishmeal and fish oil substitution, soybean protein concentrate, soybean oil

\section{INTRODUÇÃO}

A farinha e o óleo de peixe são os principais ingredientes nas formulações de rações para camarões marinhos. A primeira é fonte de

Recebido em 19 de outubro de 2017

Aceito em 9 de março de 2018

E-mail: mbtesser@gmail.com proteína de alta qualidade, apresenta fácil digestão e bom perfil de aminoácidos, enquanto o segundo é a única fonte lipídica disponível comercialmente que apresenta o ácido eicosapentaenoico (EPA) e o ácido docosahexaenoico (DHA) (Nutrient..., 2011). 
O crescimento da indústria aquícola está diretamente relacionado ao aumento na produção de alimento para peixes e camarões, e, portanto, há a necessidade de maior utilização de farinha de peixe e óleo de peixe. No entanto, nas últimas décadas, a produção mundial desses ingredientes encontra-se estagnada (The State..., 2016). Assim, a busca por alimentos alternativos que possam reduzir ou eliminar a farinha e o óleo de peixe das dietas para aquicultura é fundamental não só para dar sustentabilidade ao setor como também pelos elevados custos dessas matériasprimas (Shepherd e Jackson, 2013).

O concentrado proteico de soja (CPS) apresenta como características elevado valor de proteína bruta (65\% aproximadamente), bem como reduzido valor de carboidratos solúveis e de fatores antinutricionais (Sá et al., 2013). Por isso, é considerado um potencial substituto da farinha de peixe em rações para crustáceos e peixes (Gatlin et al., 2007; Sookying e Davis, 2012). Por outro lado, o óleo de soja é rico em ácido linoleico (18:2 n-6) e tem sido introduzido para substituir parcialmente o óleo de peixes em $L$. vannamei (Zhou et al., 2007).

O sistema de bioflocos (BFT) é uma técnica sustentável utilizada para a produção de camarões com zero troca de água (Avnimelech et al., 2008). Os bioflocos gerados dentro do sistema de criação são consumidos pelos camarões aportando nutrientes a eles (Wasielesky et al., 2006). Ainda, Xu et al. (2012) demonstraram que é possível a redução da concentração de proteína bruta de $35 \%$ para $25 \%$ da ração quando juvenis de L. vannamei são criados em sistema de bioflocos, o que revela que os bioflocos contribuem com proteína para os camarões. Portanto, o objetivo deste estudo foi avaliar os efeitos da substituição parcial e total concomitantemente da farinha e do óleo de peixe por concentrado proteico e óleo de soja no desempenho dos camarões criados em sistemas BFT.

\section{MATERIAL E MÉTODOS}

O estudo foi realizado no Laboratório de Carcinocultura, pertencente ao Instituto de Oceanografia - Furg. Com o objetivo de evitar alterações nos parâmetros de qualidade de água, bem como que ocorresse formação diferenciada de bioflocos entre os diferentes tratamentos, optou-se por trabalhar com um sistema de recirculação de água seguindo a metodologia descrita por Fóes et al. (2011). O sistema era composto por 15 tanques circulares de fibra de vidro com 150 litros de volume útil, conectados a um tanque matriz com área de $10 \mathrm{~m}^{2}$ e capacidade de 5.000 litros. Os juvenis de $L$. vannamei $(2,93 \pm 0,83 \mathrm{~g})$ foram estocados com 300 camarões $/ \mathrm{m}^{2}$. A água era bombeada do tanque matriz para as diferentes unidades experimentais, com vazão de $1,25 \mathrm{~L} / \mathrm{mim}$, e o retorno das unidades experimentais ao tanque matriz ocorreu por gravidade.

Durante o experimento, foram realizadas pequenas renovações de água do tanque matriz para redução do nitrito e também dos níveis de sólidos suspensos totais. Aplicações de probiótico (Sanolife Pro-W ${ }^{\circledR}$ - INVE) foram realizadas semanalmente no tanque matriz, na proporção de $1 \mathrm{ppm}$, calculado para o volume total do sistema (tanque matriz +15 unidades), com o objetivo de auxiliar na redução da matéria orgânica do sistema e evitar a presença de víbrios.

Para o desenvolvimento deste estudo, foram formuladas cinco dietas com diferentes níveis de substituição concomitantes da farinha e do óleo de peixe por farinha e óleo de origem vegetal. Para a substituição da farinha de peixe (FP), foi utilizado concentrado proteico de soja (CPS) e, para a substituição do óleo de peixe (OP), foi utilizado o óleo de soja (OS). Os níveis de substituição testados foram $0 \%$ (sem substituição, dieta controle), $25 \%, 50 \%, 75 \%$ e $100 \%$, respectivamente, compondo, dessa forma, cinco tratamentos. Os tratamentos foram realizados com três repetições, e os tanques distribuídos de forma aleatória.

A ração foi ofertada duas vezes ao dia, no início da manhã e ao final da tarde, em bandejas de alimentação a uma taxa inicial de arraçoamento de $7,5 \%$ da biomassa de cada unidade. A quantidade de ração ofertada aos camarões foi ajustada semanalmente de acordo com as biometrias, seguindo a metodologia proposta por Jory et al. (2001). Biometrias semanais foram realizadas utilizando-se 15 camarões de cada unidade, os quais foram pesados em balança de precisão $( \pm 0,01 \mathrm{~g})$ e posteriormente devolvidos para o seu tanque de origem. 
A composição proximal dos alimentos foi analisada no Laboratório de Nutrição de Organismos Aquáticos (Lanoa) da Universidade Federal do Rio Grande (Furg). A matéria seca (MS) foi determinada por meio de estufa a $102^{\circ} \mathrm{C}$ por cinco horas. Para a análise de cinzas (MM), as amostras foram calcinadas em mufla a $600^{\circ} \mathrm{C}$ por cinco horas. A proteína bruta (PB) foi determinada de acordo com a metodologia de Kjeldahl, após digestão da amostra e destilação do nitrogênio, multiplicando-se o resultado por 6,25; o extrato etéreo (EE), no extrator de Soxhlet, utilizando-se o éter de petróleo como solvente por seis horas (Official..., 2000).

Para formulação das dietas, os ingredientes foram pesados e triturados até a obtenção de um pó de aproximadamente de $300 \mu \mathrm{m}$.
Primeiramente, foram misturados os ingredientes secos e, em seguida, adicionados os óleos e a água destilada, até a formação de uma massa consistente e homogênea. Essa massa foi passada por um moedor para obtenção da ração com diâmetro médio de $3 \mathrm{~mm}$. Os pellets foram transferidos para bandejas de aço inox e secos em estufa a $60^{\circ} \mathrm{C}$ por oito horas. Após esse período, foram armazenados em sacos plásticos e mantidos $\mathrm{a}-18^{\circ} \mathrm{C}$ até o momento da utilização.

As dietas foram formuladas para conterem aproximadamente $35 \%$ de proteína bruta, $8 \%$ de lipídios e $4200 \mathrm{kcal} / \mathrm{kg}$ de energia bruta. A composição das dietas, os percentuais dos seus ingredientes, assim como a composição proximal de cada uma delas, estão apresentados na Tab. 1.

Tabela 1. Composição das dietas experimentais $(\mathrm{g} / 100 \mathrm{~g}$ de peso seco) e composição proximal (g/100g de peso seco, $n=3$ ) das dietas contendo níveis crescentes de substituição da farinha e do óleo de peixe por concentrado proteico e óleo de soja

\begin{tabular}{lccccc}
\hline \multicolumn{1}{c}{ Alimentos } & \multicolumn{5}{c}{ Dietas $(\%$ de substituição da farinha e do óleo de peixe) } \\
\hline Farinha de peixe & 0 & 25 & 50 & 75 & 100 \\
CPS $^{1}$ & 33,0 & 24,75 & 16,50 & 8,25 & 0,0 \\
Farelo de soja & 0,0 & 7,50 & 15,0 & 22,50 & 30,0 \\
Farelo de trigo & 18,0 & 18,0 & 18,0 & 18,0 & 18,0 \\
Amido de milho & 14,0 & 14,0 & 14,0 & 14,0 & 14,0 \\
Levedura de cerveja & 22,0 & 21,0 & 20,0 & 19,0 & 18,0 \\
Óleo de peixe & 5,0 & 5,0 & 5,0 & 5,0 & 5,0 \\
Óleo de soja & 3,0 & 2,25 & 1,50 & 0,75 & 0,0 \\
Celulose & 0,0 & 1,90 & 3,80 & 5,70 & 7,60 \\
Carboximetilcelulose & 0,0 & 0,60 & 1,20 & 1,80 & 2,40 \\
Mist. mineral e vit. & 2,0 & 2,0 & 2,0 & 2,0 & 2,0 \\
Ca(H ${ }_{2}$ PO $\left._{4}\right)_{2}$ & 1,0 & 1,0 & 1,0 & 1,0 & 1,0 \\
Total & 2,0 & 2,0 & 2,0 & 2,0 & 2,0 \\
Análise proximal & 100 & 100 & 100 & 100 & 100 \\
Proteína & & & & $33,5 \pm 0,1$ & $33,7 \pm 0,7$ \\
Extrato etéreo & $33,6 \pm 1,3$ & $33,3 \pm 1,1$ & $33,6 \pm 0,8$ & $10,5 \pm 1,4$ & $9,3 \pm 0,3$ \\
Cinzas & $9,5 \pm 0,2$ & $7,2 \pm 0,1$ & $9,1 \pm 0,1$ & $7,5 \pm 0,1$ & $6,4 \pm 0,5$ \\
Umidade & $11,7 \pm 0,5$ & $10,4 \pm 0,7$ & $8,7 \pm 0,5$ & $5,8 \pm 0,1$ & $5,2 \pm 0,2$ \\
\hline
\end{tabular}

${ }^{1}$ CPS - concentrado proteico de soja. IMCOPA (Imcosoy 60) Araucária, PR, Brasil.

${ }^{2}$ Vitamina A $(500.000 \mathrm{Ul} / \mathrm{kg})$, vit. D3 (250.000Ul/ kg), vit. E $(5.000 \mathrm{mg} / \mathrm{kg})$, vit. K3 $(500 \mathrm{mg} / \mathrm{kg})$, vit. B1 $(1.000 \mathrm{mg} / \mathrm{kg})$, vit. B2 $(1.000 \mathrm{mg} / \mathrm{kg})$, vit. B6 $(1.000 \mathrm{mg} / \mathrm{kg})$, vit. B12 $(2.000 \mathrm{mcg} / \mathrm{kg})$, niacina $(2.500 \mathrm{mg} / \mathrm{kg})$, pantotenato de cálcio $(4.000 \mathrm{mg} / \mathrm{kg})$, ácido fólico $(500 \mathrm{mg} / \mathrm{kg})$, biotina $(10 \mathrm{mg} / \mathrm{kg})$, vit. C $(10.000 \mathrm{mg} / \mathrm{kg})$, colina $(100.000 \mathrm{mg} / \mathrm{kg})$, inositol $(1.000 \mathrm{mg} / \mathrm{kg})$, selênio $(30 \mathrm{mg} / \mathrm{kg})$, ferro $(5.000 \mathrm{mg} / \mathrm{kg})$, cobre $(1.000 \mathrm{mg} / \mathrm{kg})$, manganês $(5.000 \mathrm{mg} / \mathrm{kg})$, zinco $(9.000 \mathrm{mg} / \mathrm{kg})$, cobalto $(50 \mathrm{mg} / \mathrm{kg})$, iodo $(200 \mathrm{mg} / \mathrm{kg})$.

Durante o período experimental, o oxigênio dissolvido (oxímetro digital - YSI $^{\circledR}$ modelo 55, Yellow Springs, OH, USA), a temperatura e o pH (pH-metro digital - YSI ${ }^{\circledR}$ Ecosense pH 100, Yellow Springs, OH, USA) foram medidos duas vezes ao dia em todas as unidades experimentais. A temperatura foi controlada com o uso de aquecedores distribuídos no tanque matriz, e a aeração foi provida por meio de soprador de ar conectado a mangueiras com pedras porosas 
alocadas em todas as unidades experimentais e no tanque matriz, para promover a oxigenação da água e manter os bioflocos em suspensão na coluna da água. A salinidade (refratômetro modelo RTS-101, Atago ${ }^{\circledR}$ US, Bellevue, WA, USA) foi mantida em torno de $33 \%$, sendo realizada reposição das perdas por evaporação utilizando-se água doce.

Coletas de água foram realizadas diariamente para o acompanhamento das variações da amônia total (Manual..., 1983), nitrito (Strickland and Parsons, 1972) e alcalinidade (Standard..., 1998). As concentrações de nitrato e fosfato da água foram analisadas semanalmente seguindo as metodologias propostas por Strickland e Parsons (1972). O fotoperíodo foi de $12 \mathrm{~h}$ claro: $12 \mathrm{~h}$ escuro, com iluminação artificial durante o período experimental.

A análise dos sólidos suspensos totais ( $\mathrm{mg} / \mathrm{L}$ ) foi realizada seguindo a metodologia proposta por Strickland e Parsons (1972), duas vezes por semana, por gravimetria mediante filtragem de alíquotas de $20 \mathrm{~mL}$ de água em filtros de fibra de vidro GF 50-A. Os filtros foram colocados previamente para secar em estufa a $60^{\circ} \mathrm{C}$, até retirada total da umidade, e pesados. Após a filtragem, recolocados na estufa por $24 \mathrm{~h}$ e pesados em balança analítica de precisão (Sartorius MC1, analytic AC 210S) até o peso constante, para determinação de peso final. O valor dos sólidos foi estimado pela diferença entre peso inicial e final de cada filtro (Official..., 2000). O volume total dos flocos $(\mathrm{mL} / \mathrm{L})$ foi obtido com uso de cones ImHoff. Para tal, amostras individuais de um litro de água, de cada unidade experimental, foram colocadas em cones plásticos por 15 minutos. Posteriormente, foi observado o conteúdo de flocos (Avnimelech, 2007).

Ao final dos 49 dias de experimento, foi realizada uma biometria com todos os camarões, obtendo-se o peso médio final em cada unidade experimental. Dessa forma, os seguintes parâmetros foram calculados:

peso médio final $(\mathrm{PF}=$ somatória do peso final de todos os camarões vivos / total dos camarões vivos);

ganho de peso $(\mathrm{GP}=$ peso médio final - peso médio inicial); conversão alimentar $(\mathrm{CA}=$ ração fornecida / peso inicial - peso final);

taxa de crescimento específico $(\mathrm{TCE}=[(\ln$ peso final - In peso inicial)/dias de criação] $\times 100$ ); biomassa final $=$ somatória do peso final de todos os camarões vivos e a sobrevivência $(\mathrm{S}=$ quantidade final de animais / quantidade inicial dos animais $\times 100$ ).

Análises da composição proximal dos bioflocos e do músculo dos camarões foram realizadas ao final do experimento. Para as análises dos bioflocos, foi coletada uma amostra da água do tanque matriz, a qual foi filtrada, através de malha de $50 \mu \mathrm{m}$, até se obter uma massa de bioflocos úmidos $(\sim 500 \mathrm{~g})$, que logo foram secos em estufa a $105^{\circ} \mathrm{C}$ por oito horas e, posteriormente, armazenados a $-18^{\circ} \mathrm{C}$, até que fosse realizada a análise proximal. Para a análise do músculo, foram coletados sete camarões de cada tanque. Os músculos foram homogeneizados até se tornarem uma massa e, em seguida, secos em estufa a $105^{\circ} \mathrm{C}$. A composição proximal foi determinada de acordo com metodologia proposta pela AOAC (Official.., 2000).

Após atenderem as premissas de normalidade (teste de Shapiro-Wilk) e homocedasticidade (teste de Levene), os dados foram analisados por ANOVA de uma via, para se verificar o efeito das cinco dietas testadas, no desempenho e na análise proximal do músculo dos camarões. Quando foi observada diferença estatística entre as médias, o teste post-hoc de Tukey foi realizado, com um nível de significância de $5 \%$.

\section{RESULTADOS}

Os resultados dos parâmetros de qualidade de água não apresentaram diferenças estatísticas entre os tratamentos e, dessa forma, foram agrupados. Os valores médios da temperatura foram de $28 \pm 1^{\circ} \mathrm{C}$, o oxigênio dissolvido foi de $5,80 \pm 0,49 \mathrm{mg} / \mathrm{L}, \quad$ o $\quad \mathrm{pH} 7,8 \pm 0,2$, a salinidade $33 \% 0 \pm 1$, a alcalinidade $150 \pm 13 \mathrm{mg} / \mathrm{L} \mathrm{CaCO}_{3}$, a amônia total $\mathrm{N}$-AT $0,06 \pm 0,12 \mathrm{mg} / \mathrm{L}$, o nitrito $\mathrm{N}$ $\mathrm{NO}_{2} \quad 3,12 \pm 5,64 \mathrm{mg} / \mathrm{L}, \quad$ o nitrato $\quad \mathrm{N}^{-\mathrm{NO}_{3}}$ $75,60 \pm 35,85 \mathrm{mg} / \mathrm{L}, \quad \mathrm{o}$ fosfato $\mathrm{P}_{-} \mathrm{PO}^{3}{ }_{4}$ $3,39 \pm 1,10 \mathrm{mg} / \mathrm{L}$, e os sólidos suspensos totais foram de SST $571,0 \pm 140,7 \mathrm{mg} / \mathrm{L}$.

Os valores médios dos indicadores do desempenho zootécnico dos camarões são 
apresentados na Tab. 2. Não foi evidenciada diferença significativa $(\mathrm{P}>0,05)$ para peso médio final, ganho em peso e ganho em peso semanal, para a taxa de conversão alimentar e sobrevivência entre os tratamentos. No entanto, a taxa de crescimento específico apresentou menor valor $(\mathrm{P}<0,05)$ para os camarões alimentados com $100 \%$ de substituição da farinha e do óleo de peixe, quando comparados àqueles dos demais tratamentos. Os resultados de biomassa final apresentaram diferenças significativas entre os tratamentos. O tratamento com $100 \%$ de substituição apresentou resultado de final de biomassa estatisticamente menor do que os camarões do tratamento sem substituição e com $25 \%$ de substituição, enquanto os camarões dos tratamentos 50 e $75 \%$ de substituição apresentaram valores intermediários (Tab. 2).

Tabela 2. Indicadores do desempenho zootécnico dos juvenis de L. vannamei alimentados com dietas contendo diferentes níveis da substituição da farinha e do óleo de peixe por concentrado proteico e óleo de soja durante 49 dias de experimento

\begin{tabular}{ccccccc}
\hline Tratamentos & $\begin{array}{c}\text { PF } \\
(\mathrm{g})\end{array}$ & $\begin{array}{c}\text { GP } \\
(\mathrm{g})\end{array}$ & TCE & CA & $\begin{array}{c}\text { BF } \\
(\mathrm{g})\end{array}$ & $\begin{array}{c}\text { S } \\
(\%)\end{array}$ \\
\hline 0 & $8,56 \pm 0,32$ & $5,67 \pm 0,31$ & $3,00 \pm 0,12^{\mathrm{a}}$ & $2,03 \pm 0,19$ & $378,10 \pm 17,14^{\mathrm{a}}$ & $97,78 \pm 3,85$ \\
25 & $8,92 \pm 0,44$ & $6,00 \pm 0,48$ & $3,02 \pm 0,17^{\mathrm{a}}$ & $2,27 \pm 0,19$ & $380,20 \pm 22,62^{\mathrm{a}}$ & $94,82 \pm 2,57$ \\
50 & $8,63 \pm 0,63$ & $5,73 \pm 0,66$ & $2,88 \pm 0,14^{\mathrm{a}}$ & $2,19 \pm 0,25$ & $362,63 \pm 18,38^{\mathrm{ab}}$ & $93,33 \pm 2,22$ \\
75 & $8,71 \pm 0,41$ & $5,76 \pm 0,41$ & $2,89 \pm 0,06^{\mathrm{a}}$ & $2,35 \pm 0,07$ & $362,83 \pm 8,50^{\mathrm{ab}}$ & $92,59 \pm 2,57$ \\
100 & $7,78 \pm 0,57$ & $4,90 \pm 0,56$ & $2,54 \pm 0,08^{\mathrm{b}}$ & $2,53 \pm 0,37$ & $321,66 \pm 9,64^{\mathrm{b}}$ & $91,86 \pm 5,13$ \\
\hline
\end{tabular}

Letras diferentes na mesma linha indicam que as médias diferem significativamente $(\mathrm{P}<0,05)$. Dados apresentados como média \pm desvio-padrão. Tratamentos (T), peso médio final (PF), ganho de peso (GP), ganho de peso semanal (GPS), taxa de crescimento específico (TCE), taxa de conversão alimentar (CA), biomassa final (BF) e sobrevivência (S).

As composições musculares dos camarões, bem como a composição dos bioflocos, estão apresentadas na Tab. 3. A composição proximal do músculo dos camarões não apresentou diferença significativa $(\mathrm{P}>0,05)$ entre os diferentes tratamentos.

Tabela 3. Composição proximal (\%) do músculo de juvenis de camarão (g/100g de peso úmido) alimentados com dietas contendo diferentes níveis de substituição da farinha e do óleo de peixe por concentrado proteico e óleo de soja e dos bioflocos ( $\mathrm{g} / 100 \mathrm{~g}$ de peso seco) ao final do período experimental. Valores apresentados como média \pm desvio-padrão $(\mathrm{n}=9)$

\begin{tabular}{ccccc}
\hline Tratamentos & Proteína & Extrato etéreo & Umidade & Cinzas \\
\hline 0 & $20,77 \pm 0,43$ & $2,49 \pm 0,11$ & $75,70 \pm 0,71$ & $2,78 \pm 0,04$ \\
25 & $20,27 \pm 0,93$ & $2,51 \pm 0,9$ & $75,92 \pm 0,65$ & $2,58 \pm 0,28$ \\
50 & $20,62 \pm 0,90$ & $2,84 \pm 0,15$ & $76,23 \pm 0,35$ & $2,57 \pm 0,06$ \\
75 & $20,69 \pm 0,44$ & $2,40 \pm 0,30$ & $76,12 \pm 0,65$ & $2,49 \pm 0,01$ \\
100 & $20,83 \pm 0,35$ & $2,39 \pm 0,15$ & $76,01 \pm 0,74$ & $2,37 \pm 0,09$ \\
Biofloco & $31,27 \pm 0,16$ & $2,93 \pm 0,41$ & $9,19 \pm 0,10$ & $26,32 \pm 0,09$ \\
\hline
\end{tabular}

\section{DISCUSSÃO}

O NRC (Nutrient..., 2011) apregoa que estudos sobre a busca de alimentos alternativos à farinha e ao óleo de peixe são prioridades dentro da área aquícola. Neste estudo, foi verificado que a substituição conjunta da farinha e do óleo de peixe é possível até o nível de $75 \%$ pelo concentrado proteico de soja e pelo óleo de soja, desde que os camarões sejam produzidos em sistemas de bioflocos.
Os parâmetros de qualidade de água não apresentaram variações entre os tratamentos e foram mantidos dentro dos níveis recomendados para a espécie (Van Wyk e Scarpa, 1999). Os sólidos suspensos totais podem ser considerados valores intermediários, de acordo com o Gaona et al. (2017).

O concentrado proteico de soja é deficiente em metionina, lisina e triptofano (Forster et al., 2002). Além desse fato, é conhecido que altas concentrações de produtos vegetais, como a soja e outros mais utilizados em dietas para camarões, 
podem afetar negativamente a palatabilidade e digestibilidade (Sookying e Davis, 2012; Ye et al., 2012). Os bioflocos também são deficientes em aminoácidos. Em estudo recente, Wei et al. (2016) demonstraram que bioflocos produzidos de fontes de carboidratos diferentes apresentam características nutricionais diferentes, no entanto todos são considerados deficientes em metionina e histidina. Assim, ao se substituir a farinha de peixe por fontes vegetais, a suplementação com aminoácidos sintéticos se faz necessária para se atender as exigências do camarão (Nunes et al., 2014).

Por outro lado, neste estudo foi possível substituir $75 \%$ de fontes oriundas de pescado por concentrado proteico de soja, nível maior do que o relatado por Jatobá et al. (2017), que também avaliaram a substituição de farinha de peixe por concentrado proteico de soja para o camarão criado em sistema de bioflocos. Os autores relatam que o melhor nível de substituição encontrado foi de $33 \%$ da farinha de peixe. Já Chen et al. (2017) citam que apenas 25\% da farinha de peixe podem ser substituídos por concentrado proteico de soja para a mesma espécie, produzida, no entanto, em água clara. Dessa forma, apesar de os bioflocos serem deficientes em metionina, certamente sua composição nutricional contribuiu para a manutenção do crescimento dos camarões até a substituição de $75 \%$ da farinha e do óleo de peixe encontrados neste estudo.

A substituição total da farinha e do óleo de peixe também pode ter ocasionado deficiência em ácidos graxos altamente poli-insaturados (DHA 22:6n3, EPA - 20:5n3) nos camarões, uma vez que esses compostos são ausentes em óleos de origem vegetal (Nutrient..., 2011). Soma-se a isso o fato de que os camarões possuem baixa capacidade de elongação e dessaturação (Kanazawa et al., 1979; Kayama et al., 1980). Browdy et al. (2006) mencionam que é necessário pelo menos entre 1 e $2 \%$ de ácidos graxos altamente insaturados (n-3 HUFA) nas dietas para um melhor crescimento dos camarões. $\mathrm{Xu}$ et al. (2016) estudaram a substituição do óleo de peixe por óleo de soja para o camarão L. vannamei em água clara e obtiveram que o melhor valor de substituição encontrado foi de $50 \%$, nível inferior ao encontrado neste estudo, em que $75 \%$ do óleo de peixe foram substituídos por óleo de soja. O maior nível de substituição está relacionado com a contribuição da fração lipídica proveniente dos bioflocos. Toledo et al. (2016) demonstram que, em sistemas de bioflocos, as dietas para juvenis de L. vannamei podem conter menor quantidade de lipídios e, ainda, que os bioflocos são fontes de ácidos graxos poli-insaturados de cadeia longa.

Embora os bioflocos possam influenciar a composição corporal dos camarões (Kuhn et al., 2010; Xu e Pan, 2012), não foram evidenciadas diferenças na análise proximal do músculo dos camarões entre os tratamentos. Valores similares no conteúdo de proteína do músculo dos camarões mantidos em sistemas BFT foram relatados por vários autores, como $\mathrm{Xu}$ e $\mathrm{Pan}$ (2012) e Wasielesky et al. (2006), os quais reportaram níveis médios de proteína de $18,6 \%$ e $17,8 \%$, respectivamente

A conversão alimentar não apresentou diferenças entre os tratamentos. Esse fato é importante, pois demonstra que todos as rações testadas apresentaram a mesma capacidade de aportar nutrientes aos camarões. Esse mesmo fato foi descrito por Jatobá et al. (2017) ao testarem a substituição de farinha de peixe por concentrado proteico de soja para camarões em bioflocos. No entanto, os valores de conversão alimentar encontrados neste estudo foram superiores aos encontrados por Bauer et al. (2012), que também avaliaram a substituição da farinha de peixe por concentrado proteico de soja, no entanto em água clara. Os maiores valores de conversão alimentar aqui encontrados podem estar relacionados à menor estabilidade na água dos grânulos de ração.

Neste estudo, ficou demonstrado que é possível substituir grande parte de insumos de origem de pescado na formulação de rações para o camarão marinho, ajudando a minimizar a dependência desses ingredientes $\mathrm{e}$, portanto, minorar $\mathrm{o}$ impacto ambiental.

\section{CONCLUSÃO}

Nas condições experimentais utilizadas neste estudo, a farinha e o óleo de peixe podem ser substituídos concomitantemente em até $75 \%$ por fontes alternativas de origem vegetal (concentrado proteico de soja e óleo de soja) sem afetar a sobrevivência e o crescimento. Ainda, os 
resultados deste estudo permitem concluir que os bioflocos contribuem com a nutrição dos camarões $L$. vannamei e que, dessa forma, maiores níveis de substituição da farinha e do óleo de peixe por fontes vegetais podem ser alcançados neste sistema de produção comparativamente à produção de camarões em água clara.

\section{AGRADECIMENTOS}

Os autores são gratos ao $\mathrm{CNPq}$ e à Capes, pelo apoio financeiro. M.B. Tesser e Wilson Wasielesky são bolsistas de produtividade do CNPq.

\section{REFERÊNCIAS}

AVNIMELECH, Y. Feeding with microbial flocs by tilapia in minimal discharge bio-flocs technology ponds. Aquaculture, v.264, p.140147,2007

AVNIMELECH， Y.; VERDEGEM， M.C.J.; KURUP, M.; KESHAVANATH, P. Sustainable land-based aquaculture rational utilization of water, land and feed. Mediterr. Aquacul. J., v.1, p.45-55, 2008.

BAUER，W.; PRENTICE-HERNADEZ， C.; TESSER, M.B.; WASIELESKY, W.; POERSCH, L.H. Substitution of fishmeal with microbial floc meal and soy protein concentrate in diets for the Pacific white shrimp Litopenaeus vannamei. Aquaculture, v.342-343, p.112-116, 2012

BROWDY, C.; SEABORN, G.; ATWOOD, H. et al. Comparison of pond production efficiency, fatty acid profiles, and contaminants in Litopenaeus vannamei fed organic plant-based and fish-meal-based diets. J. World Aquacul. Soc., v.37, p.437-451, 2006.

CHEN, J.; LI, X.; XU, H.; SUN, W.; LENG, X. Substitute of soy protein concentrate for fish meal in diets of white shrimp (Litopenaeus vannamei Boone). Aquacul. Int., v.25, p.13031315, 2017.

FÓES, G.K.; FRÓES, C.; KRUMMENAUER, D.; POERSCH, L.; WASIELESKY, W. Nursery of pink shrimp Farfantepenaeus paulensis in biofloc technology culture system: survival and growth at different stocking densities. J. Shellfish Res., v.30, p.367-373, 2011.
FORSTER, I.P.; DOMINY, W.; TACON, A. The use of concentrates and other soy products in shrimp feeds. In: CRUZ-SUAREZ, L.E.; RICQUEMARIE, D.; TAPIA-SALAZAR, M.; GAXIOLACORTES, M.G.; SIMOES, N. (Eds.). In: AVANCES EN NUTRICIÓN ACUÍCOLA/MEMORIAS DEL SIMPOSIUM INTERNACIONAL DE NUTRICIÓN ACUÍCOLA, 6., 2002, Cancún, Proceedings..., Cancún: UANL, 2002. p.3-6.

GAONA, C.A.P.; ALMEIDA, M.S.; VIAU, V. et al. Effect of different total suspended solids levels on a Litopenaeus vannamei (Boone, 1931) BFT culture system during biofloc formation. Aquacul. Res., v.48, p.1070-1079, 2017.

GATLIN, D.M.; BARROWS, F.T.; BROWN, P. et al. Expanding the utilization of sustainable plant products in aqua feeds: a review. Aquacul. Res., v.38, p.551-579, 2007.

JATOBÁ, A.; VIERA, F.N.; SILVA, B.C. et al. Replacement of fishmeal for soy protein concentrate in diets for juvenile Litopenaeus vannamei in biofloc-based rearing system. Rev. Bras. Zootec., v.46, p.705-713, 2017.

JORY, D.E.; CABRERA, T.R.; DUGGER, D.M. et al. A global review of shrimp feed management: status and perspectives. In: BROWDY, C.L., JORY, D.E. (Eds.). In: THE NEW WAVE, PROCEEDINGS OF THE SPECIAL SESSION ON SUSTAINABLE SHRIMP CULTURE, AQUACULTURE, 2001, Baton Rouge. Proceedings... Baton Rouge, LA: World Aquaculture Society, 2001. p.104-152.

KANAZAWA, A.; TESHIMA, S.; ONO, K. Relationship between essential fatty acid requirements of aquatic animals and the capacity of bioconversion of linolenic acid in highly unsaturated fatty acid. Comp. Biochem. Physiol., v.63, p.295-298, 1979.

KAYAMA, M.; HIRATA, M.; KANAZAWA, A.; TOKIWA, S.; SAITO, M. Essential fatty acids in the diet of prawn-III. Lipid metabolism and fatty acid composition. Bull. Jpn. Soc. Sci. Fish., v.46, p.483-488, 1980.

KUHN, D.D.; LAWRENCE, A.L.; BOARDMAN, G.D. et al. Evaluation of two types of bioflocs derived from biological treatment of fish effluent as feed ingredients for Pacific white shrimp, Litopenaeus vannamei. Aquaculture, v.303, p.28-33, 2010. 
MANUAL and guides 12, Intergovernmental Oceanographic Commissiony. Paris: UNESCO, 1983. (Chemical methods for use in marine environmental monitoring).

NUNES, A.J.P.; SÁ, M.V.C.; BROWDY, C.L.; VAZQUEZ-ANON, M. Practical supplementation of shrimp and fish feeds with crystalline amino acids. Aquaculture, v.431, p.20-27, 2014.

NUTRIENT requirement of fish and shrimp. Washington: National Academy Press, 2011.

OFFICIAL methods of analysis. 16.ed. Washington: National Academy Press, 2011.

SÁ, M.V.C.; SABRY-NETO, H.; CORDEIROJÚNIOR, E.; NUNES, A.J.P. Dietary concentrations of marine oils affects replacement of fish meal by soy bean concentrate in practical diets for the white shrimp, Litopenaeus vannamei. Aquacul. Nutr., v.19, p.199-210, 2013.

SHEPHERD, C.J.; JACKSON, A.J. Global fishmeal and fish-oil supply: inputs, outputs and markets. J. Fish Biol., v.83, p.1046-1066, 2013.

SOOKYING, D.; DAVIS, D.A. Use of soy protein concentrate in practical diets for Pacific white shrimp (Litopenaeus vannamei) reared under field conditions. Aquacult. Int., v.20, p.357-371, 2012.

STANDARD methods for the examination of water and waste water. 20.ed. Washington: APHA, 1193. p.1998.

STRICKLAND， J.D.H.; PARSONS, T.R. A practical handbook of seawater analysis. Ottawa: Fishery Research Board Canada, 1972. 310p.

THE STATE of World Fisheries and Aquaculture 2016. Rome: FAO/Food and Agriculture Organization of the United Nations, 2016. 200p.

TOLEDO, T.M.; SILVA, B.C.; VIEIRA, F.N.; MOURINHO, J.L.P.; SEIFFERT, W.Q. Effects of different dietary lipid levels and fatty acids profile in the culture of white shrimp Litopenaeus vannamei (Boone) in biofloc technology: water quality, biofloc composition, growth and health. Aquacul. Res., v.47, p.18411851, 2016.
VAN WYK, P.; SCARPA, J. Water quality requirements and management. In: VAN WYK, P.; DAVIS-HODGKINS, M.; LARAMORE, R.; MAIN, K.; MOUNTAIN, J.; SCARPA, J. (Eds.). Farming marine shrimp in recirculating freshwater systems. Florida: Department of Agriculture and Consumer Services, 1999. 128p.

WASIELESKY, W.; ATWOOD, H.; STOKES, A.; BROWDY, C.L. Effect of natural production in a zero exchange suspended microbial flocs based super-intensive culture system for white shrimp Litopenaeus vannamei. Aquaculture, v.258, p.396-403, 2006.

WEI, Y.F.; LIAO, S.A.; WANG, A.L. The effect of different carbon sources on the nutritional composition, microbial community and structure of bioflocs. Aquaculture, v.465, p.88-93, 2016.

XU, W.J.; PAN, L.Q. Effects of bioflocs on growth performance, digestive enzyme activity and body composition of juvenile Litopenaeus vannamei in zero-water exchange tanks manipulating $\mathrm{C} / \mathrm{N}$ ratio in feed. Aquaculture, v.356-357, p.147-152, 2012.

XU, W.J.; PAN, L.Q.; ZHAO, D.H.; HUANG, J. Preliminary investigation into the contribution of bioflocs on protein nutrition of Litopenaeus vannamei fed with different dietary protein levels in zero-water exchange culture tanks. Aquaculture, v.350-353, p.147-153, 2012.

XU, Z.; WANG, A.; WANG, H.; ZHANG, H. The effect of replacement of fish oil by soybean oil in practical diets, on tissue fatty acid and expression of related genes in Pacific white shrimp Litopenaeus vannamei. Isr. J. Aquacul. Bamidgeh, v.68, p.1-9, 2016.

YE, J.D.; LIU, X.H.; KONG, J.H. et al. The evaluation of practical diets on a basis of digestible crude protein, lysine and methionine for Litopenaeus vannamei. Aquacul. Nutr., v.18, p.651-661, 2012.

ZHOU, Q.C.; LI, C.C.; LIU, C.W.; CHI, S.Y.; YANG, Q.H. Effects of dietary lipid sources on growth and fatty acid composition of juvenile shrimp, Litopenaeus vannamei. Aquacul. Nutr., v.13, p.222-229, 2007. 